\title{
(2) OPEN ACCESS \\ US Army basic combat training alters the relationship between body mass index and per cent body fat
}

\author{
Stephen A Foulis 이 , J M Hughes, B A Spiering, L A Walker, K I Guerriere, K M Taylor, \\ S P Proctor, K E Friedl
}

USARIEM, Natick, Massachusetts, USA

\section{Correspondence to} Dr K E Friedl, USARIEM, Natick, Massachusetts, USA; karl.e. friedl3.civ@mail.mil

Received 2 July 2021 Accepted 3 August 2021

Check for updates

(C) Author(s) (or their employer(s)) 2021. Re-use permitted under CC BY-NC. No commercial re-use. See rights and permissions. Published by BMJ.

To cite: Foulis SA,
Hughes JM, Spiering BA,
et al. BMJ Mil Health Epub
ahead of print: [please
include Day Month Year].
doi:10.1136/
bmjmilitary-2021-001936

\begin{abstract}
Introduction/background As a proxy for adiposity, body mass index (BMI) provides a practical public health metric to counter obesity-related disease trends. On an individual basis, BMI cannot distinguish fat and lean components of body composition. Further, the relationship between BMI and body composition may be altered in response to physical training. We investigated this dynamic relationship by examining the effect of US Army basic combat training (BCT) on the association between $\mathrm{BMI}$ and per cent body fat (\%BF).

Methods $\mathrm{BMI}$ and \%BF were measured at the beginning (week 1) and end (week 9) of BCT in female ( $n=504)$ and male $(n=965)$ trainees. Height and weight were obtained for BMI, and body composition was obtained by dual X-ray absorptiometry. Sensitivity and specificity of BMI-based classification were determined at two BMI thresholds $\left(25 \mathrm{~kg} / \mathrm{m}^{2}\right.$ and $\left.27.5 \mathrm{~kg} / \mathrm{m}^{2}\right)$.

Results A progressive age-related increase in fat-free mass index (FFMI) was observed, with an inflection point at age 21 years. In soldiers aged 21+, BMI of $25.0 \mathrm{~kg} /$ $\mathrm{m}^{2}$ predicted $33 \%$ and $29 \% \mathrm{BF}$ in women and $23 \%$ and $20 \% \mathrm{BF}$ in men and BMI of $27.5 \mathrm{~kg} / \mathrm{m}^{2}$ predicted $35 \%$ and $31 \% \mathrm{BF}$ in women and $26 \%$ and $22 \% \mathrm{BF}$ in men, at the start and end of $B C T$, respectively. Sensitivity and specificity of BMI-based classification of \%BF were poor. Soldiers below BMI of $20 \mathrm{~kg} / \mathrm{m}^{2}$ had normal instead of markedly reduced \% $\mathrm{BF}$, reflecting especially low FFMI.

\section{Key messages}

- Body mass index (BMI) is commonly used to classify obesity but cannot distinguish fat and lean components of body composition.

- The threshold of clinical overweight (BMI $25.0 \mathrm{~kg} / \mathrm{m}^{2}$ ) has low precision in classifying high body fat in healthy young women ( $>30 \%$ body fat) and men ( $>20 \%$ body fat).

- US Army basic combat training alters the relationship between $\mathrm{BMI}$ and relative body fat (per cent body fat, \%BF), with lower \%BF at a given $\mathrm{BMI}$ at the end of training.

- Young age ( $<21$ years) further affects the relationship between $\mathrm{BMI}$ and \%BF due to lower fat-free mass index compared with older women and men.

- Low BMI $\left(<20 \mathrm{~kg} / \mathrm{m}^{2}\right)$ was associated with relative body fat of normal fit women and men, reflecting markedly reduced fat-free mass and fat-free mass indices.

- Application of BMI to infer \%BF may have continuing utility in health risk assessment, especially combined with other clinically available data and waist circumference, but requires a careful re-examination in its use to assess soldier physical readiness.
\end{abstract}

Conclusions $\mathrm{BCT}$ alters the BMI-\%BF relationship, with lower \%BF at a given BMI by the end of BCT compared with the beginning, highlighting the unreliability of BMI to try to estimate body composition. The specific BMI threshold of $25.0 \mathrm{~kg} / \mathrm{m}^{2}$, defined as 'overweight', is an out-of-date metric for health and performance outcomes. To the extent that $\% \mathrm{BF}$ reflects physical readiness, these data provide evidence of a fit and capable military force at BMl greater than $25.0 \mathrm{~kg} / \mathrm{m}^{2}$.

\section{INTRODUCTION}

In the US and UK armies, height and weight are usually the primary data available to estimate obesity prevalence, and these data have often been extrapolated to interpretations about fitness of the force. In both armies, height/weight tables are combined with an assessment of waist circumference or body circumference-based body fat estimate to further refine assessments of military health and performance readiness. Unfortunately, conclusions about military readiness are often drawn simply from height and weight data. The human weight and stature relationship is properly expressed as body mass index (BMI), with weight divided by stature squared, using metric units. While an estimated half of all US and British male soldiers exceed current public health goals for Americans of BMI $<25 \mathrm{~kg} / \mathrm{m}^{2}$, this does not mean that half of soldiers are 'overweight', when overweight is defined as excess fat resulting in increased health risk or poorer performance. ${ }^{1-3}$ In fact, US soldiers are healthier and stronger than any previous generation of soldiers, with an average increase of $14 \mathrm{~kg}$ of lean mass in male soldiers over the past century along with better nutrition and medical advances. ${ }^{1}$ Sanderson et al showed that the majority of British soldiers who attempted their annual physical testing were successful in the combat fitness test and physical fitness test, but soldiers with BMI $>30$ had higher failure rates, especially those soldiers who also had had high waist circumferences. ${ }^{3}$ Additionally, the association between BMI and mortality has also shifted in recent years. An analysis of US national data by Flegal et $a l^{4}$ demonstrated the lowest mortality for men and women in national surveys has moved from a BMI of $18-25 \mathrm{~kg} / \mathrm{m}^{2}$ to the previously designated 'overweight' category, $25-30 \mathrm{~kg} / \mathrm{m}^{2}$. Together, these data suggest that 
although there are a large number of US and UK soldiers being classified as 'overweight' (ie, BMI $>25.0 \mathrm{~kg} / \mathrm{m}^{2}$ ), this categorisation may not necessarily equate directly with increased health risk or degraded performance.

$\mathrm{BMI}$ and per cent body fat $(\% \mathrm{BF})$ are correlated, but the large interindividual variation makes BMI an unsuitable predictor of the body composition of an individual. ${ }^{1}$ The use of this surrogate measure for body composition to predict physical readiness of an individual is even less suitable. This was highlighted in 1942 by Navy Commander Albert Behnke and his colleagues ${ }^{5}$ in their early investigations of the use of hydrostatic weight to estimate body composition. Professional American football players, who are large yet actually very lean, averaging $91 \mathrm{~kg}$ body mass and $8.3 \%$ body fat, could be disqualified from military service based on weight-for-height tables. ${ }^{5}$ This, and the subsequent work by Wilmore and Behnke, ${ }^{78}$ led to the development of practical anthropometric estimations of body fat to replace weight-forheight standards in the US military in the 1980s. Weight-forheight tables were retained only as a screen to determine who may require further evaluation for excess fat, with physical readiness of every member of the force as the intended objective. ${ }^{9}$

Previous studies have estimated \%BF values from existing BMI data, as BMI is the primary metric generally available to epidemiologists examining obesity-related health risk. Key factors in the interpretation of this BMI-\%BF relationship are sex and age, while race/ethnicity has only a weak influence in some studies, depending on the race and ethnic representation in the sample. ${ }^{10-14}$ Sex is necessary to consider in the interpretation of body composition due to sex-specific differences in relative body fat. Age is also an important variable, especially for military populations, where a large number of soldiers are young and still in their late phase of physical maturation. This is reflected by continuing accretion of muscle and bone mass into the third decade of life, and BMI and body composition relationships at these younger ages are changing. Sanderson et $a l^{3}$ used age 24 as the transition age for the UK sample, while the US Army uses age 21 as a transition to higher BMI and \%BF allowances; lean mass maturation falls somewhere in this early 20 s age range. At the higher reaches of \%BF and BMI, beyond the levels normally seen in healthy soldiers, the relationship between BMI and \%BF becomes curvilinear as further increases in BMI are primarily due to increases in fat mass, and accuracy of body composition measurement methods at these higher levels of BMI also becomes more tenuous. ${ }^{101115}$

Physical fitness represents an additional factor to be considered in the relationship between BMI and body composition that has not been well highlighted in previous attempts to predict $\% \mathrm{BF}$ from BMI. A recent study demonstrated that eight weeks of basic combat training (BCT) resulted in a substantial reduction in fat mass and increases in lean mass, despite relatively little net change in overall body mass. ${ }^{16}$ In the current analysis, we extend the findings of this earlier report to include the effect of physical training on the relationship between BMI and body composition.

\section{METHODS}

\section{Subjects}

These data are part of a larger prospective observational study, the ARIEM Reduction in Musculoskeletal Injury Study. ${ }^{17}$ Volunteers were trainees from seven different BCT classes at Fort Jackson, South Carolina, during 2018-2019 and included 504 female and 965 male participants. Participants provided signed informed consent for this research. Participants were 17-42 years old (mode: 18 years old; median: 19 (women), 20 (men)) and had completed a comprehensive medical screening at a Military Entrance Processing Station. In accordance with the Department of Defense Instruction 3216.20, trainees who are 17 years of age are considered adults while in federal duty status and are allowed to consent without parent or guardian approval. The predominant race and ethnicity breakdowns are as follows: $47 \%$ white, 27\% black and 21\% Hispanic for women and 61\% white, $16 \%$ black and 20\% Hispanic for men.

\section{BCT training exposure}

A key focus of BCT is physical readiness training. This is well standardised and documented. ${ }^{18} 19$ BCT is divided into three phases of training that progress from Army core values and basic soldier tasks to self-discipline, teamwork and weapons training, and finally to leadership skills and field training. Throughout the course, there is an emphasis on physical training including callisthenics, running, and combatives and physically demanding tasks such as cadence march and tactical foot marches. Previous studies have documented the progressive increase in activity energy expenditure in terms of daily steps, averaging 16000 steps/day or travel of roughly $12 \mathrm{~km} /$ day, with a peak in the field training phase near the end of BCT of 22000 steps/day or roughly $16 \mathrm{~km} /$ day. ${ }^{18} \mathrm{~A}$ more recent study with researchgrade accelerometry estimated time spent in specific activities, including $5 \%$ of total activity time in vigorous-intensity activities, with a progressive increase of moderate-vigorous activity each week for the first half of BCT. ${ }^{19}$ Sleep has been assessed as part of this current study using three sleep inventories and concluded that, initially, mean sleep exceeded seven hours per night with good quality sleep, but this was reduced for some of the soldiers later in the course. ${ }^{20}$ Food is not restricted during BCT and the Army has made continuous improvements in food service to promote healthy food choices and balanced nutritional intake. $^{21}$

\section{Procedures}

Data collection occurred during week 1 (pre-BCT) and week 9 (post-BCT). Height $(\mathrm{cm})$ was measured with a stadiometer (Model 217, SECA, Chino, California) and fasted total body mass (kg) was measured with a calibrated scale (Model 770, SECA; or Model DS6150, Doran, Batavia, Illinois), with participants in standardised physical training uniforms (athletic shorts and T-shirt) and without shoes. BMI $\left(\mathrm{kg} / \mathrm{m}^{2}\right)$ was calculated from this information.

Body composition was assessed by DXA (GE Lunar Prodigy, GE Healthcare, Madison, Wisconsin). Total body estimates of $\% \mathrm{BF}$ and fat-free mass (FFM) (kg) were determined using manufacturer-described procedures and supplied algorithms (Encore, V.11.40, Lunar, Madison, Wisconsin). Coefficient of variation for DXA \%BF measurements has been previously reported to be $<2 \% .^{22}$ Fat-free mass index (FFMI) was calculated as FFM divided by height in metres squared $\left(\mathrm{kg} / \mathrm{m}^{2}\right)$.

Statistical analyses were performed using SPSS for Windows V.24. Descriptive statistics were calculated and reported as mean $\pm S D$, and analysis of variance (ANOVA) with linear contrasts was used to assess differences by age group $(17-<21$, $21-<25,25-<29,29+$ yearsold). Significance between age groups was assessed with post-hoc Tukey adjustments. Linear regression best fit models provided $\mathrm{r}$ values and SEM. Multivariate (BMI, timepoint) regression was used to assess differences in the intercept (vertical shift) and slope of the relationship between $\mathrm{BMI}$ and \%BF pre-BCT and post-BCT. \%BF was estimated for a 
Table 1 Mean values for BMI, stature, FFMI and \%BF compared across four age categories of female and male Army recruits at entry to BCT

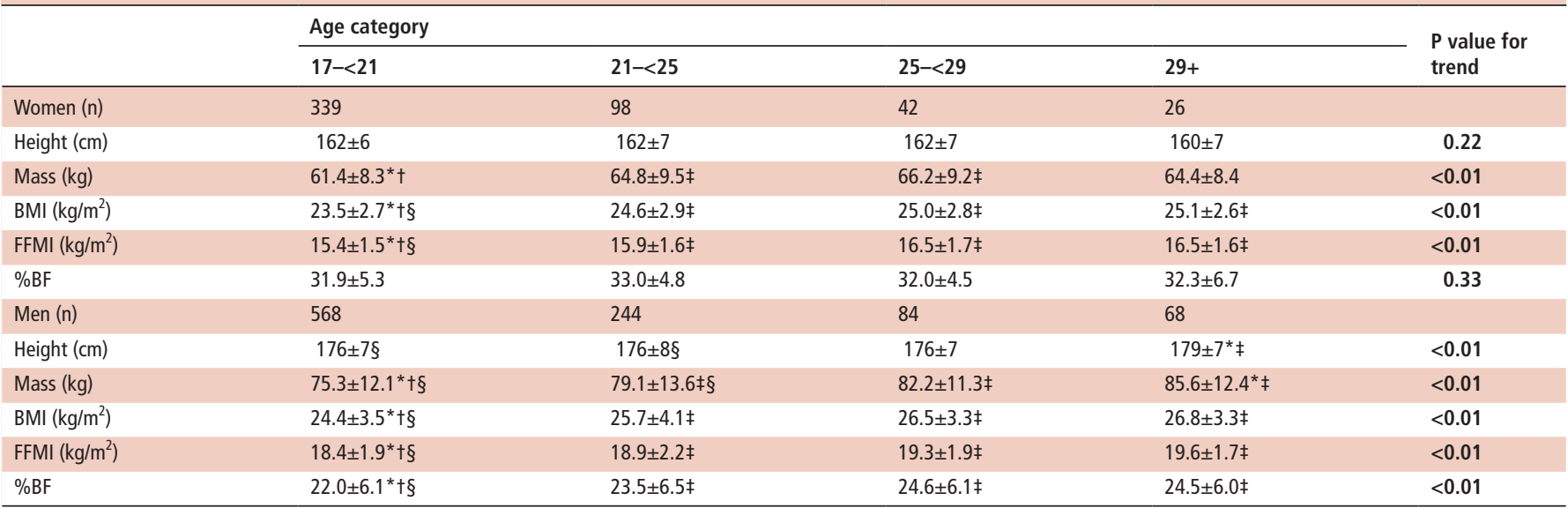

Mean \pm SD.

*Significantly different from age $21-<25, \mathrm{p}<0.05$.

†Significantly different from age $15-<29, \mathrm{p}<0.05$

\#Significantly different from age $17-<21, \mathrm{p}<0.05$.

$\S$ Significantly different from age $29+, \mathrm{p}<0.05$.

$\mathrm{BCT}$, basic combat training; \%BF, per cent body fat; BMI, body mass index; FFMI, fat-free mass index.

BMI of $25.0 \mathrm{~kg} / \mathrm{m}^{2}$ and $27.5 \mathrm{~kg} / \mathrm{m}^{2}$ (representing the full range of current US Army screening weight tables) from the linear regressions. Sensitivity and specificity were calculated for BMI cut-offs of $25.0 \mathrm{~kg} / \mathrm{m}^{2}$ and $27.5 \mathrm{~kg} / \mathrm{m}^{2}$, as well as for $\%$ BF cut-offs. Relevant Army \%BF cut-offs vary by age and sex as follows: 17-20, 21-27 and 28-39 years: 30\%, 32\% and 34\% for women and $20 \%, 22 \%$ and $24 \%$ for men, respectively.

\section{RESULTS}

Relationship between BMI, stature, FFMI and \%BF with age The mean values for BMI, stature, FFMI and \%BF were compared across four age categories in this sample of female and male Army recruits (Table 1). Across age groups, there was a significantly lower BMI and FFMI in the youngest group (age 17-<21) compared with older age categories for men and women (ANOVA with linear contrasts, $\mathrm{p}<0.02$ ). For men only, mean \%BF was also significantly lower in the youngest group (age 17-<21) compared with older age categories.

\section{Relationships between BMI and \%BF}

The relationships between BMI and \%BF are shown in Figure 1 (women) and Figure 2 (men), with individuals separated by age $<21$ and age $21+$, and with relationships shown at the start of BCT and at the end of BCT. Regression equations, linear correlations and standard estimate of the estimates $(\% \mathrm{BF})$ are shown in Table 2 . The only significant vertical shift in the regressions pre-BCT to post-BCT was in the younger men $(\mathrm{p}<0.01)$. The slopes of the lines were significantly different pre-BCT to post-BCT in both groups of men $(\mathrm{p} \leq 0.01)$ and tended to be different in younger women $(p=0.085)$.

\section{Predicted mean \%BF at BMI $25 \mathrm{~kg} / \mathrm{m}^{2}$ and $27.5 \mathrm{~kg} / \mathrm{m}^{2}$}

At the start of training, a BMI of $25.0 \mathrm{~kg} / \mathrm{m}^{2}$ predicted body fat of 34, 33\% (young and older women) and 23\% (all men). At the end of training, this was reduced to 29\% (all women) and 20\% (all men) (Table 3). At the start of training, a BMI of $27.5 \mathrm{~kg} / \mathrm{m}^{2}$ predicted 37, 35\% (young and old women) and 25\% (all men), and this reduced to $31,32 \%$ (young and older women) and 22\% (all men) at the end of BCT.
Categorisation of \%BF by BMI

The sensitivity and specificity of $\% \mathrm{BF}$ categorisation by a BMI of $25.0 \mathrm{~kg} / \mathrm{m}^{2}$ and $27.5 \mathrm{~kg} / \mathrm{m}^{2}$ for recruits at the end of training are shown for $\% \mathrm{BF}$ standards currently used by the US Army in Table 4. The results reveal poor sensitivity and specificity at a BMI threshold of $25.0 \mathrm{~kg} / \mathrm{m}^{2}$, particularly at the lower $\% B F$ standard used in the youngest recruits. At a threshold of $27.5 \mathrm{~kg} /$

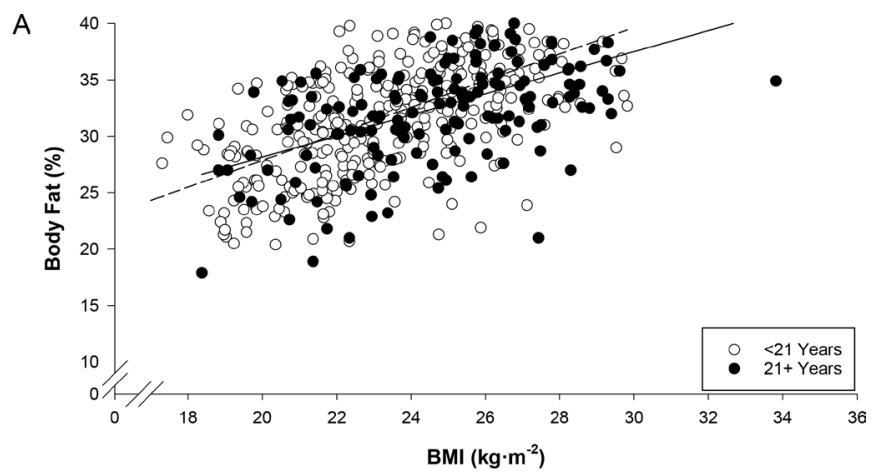

B

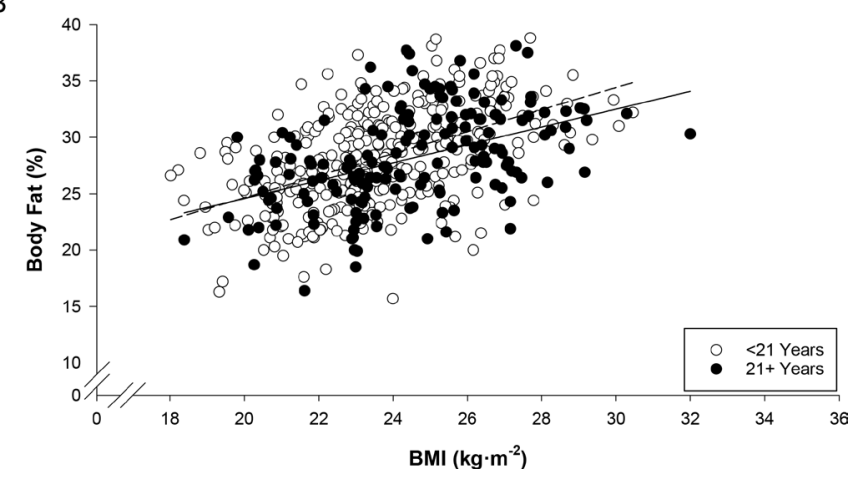

Figure 1 Relationship between $\mathrm{BMI}$ and per cent body fat in women at the start of $\mathrm{BCT}(\mathrm{A})$ and at the end of $\mathrm{BCT}(\mathrm{B})$. Data are separated by age,$<21$ years (open circles, dashed regression line) and $21+$ years (filled circles, solid regression line). BCT, basic combat training; BMI, body mass index. 
A

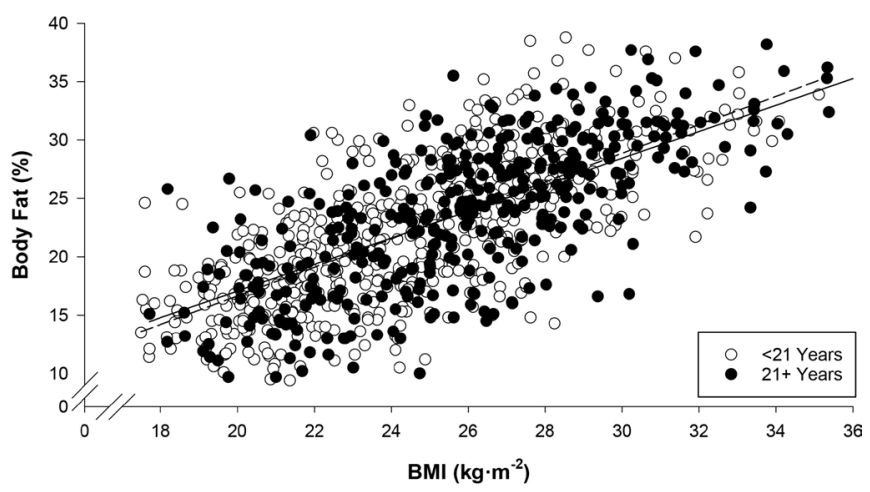

B

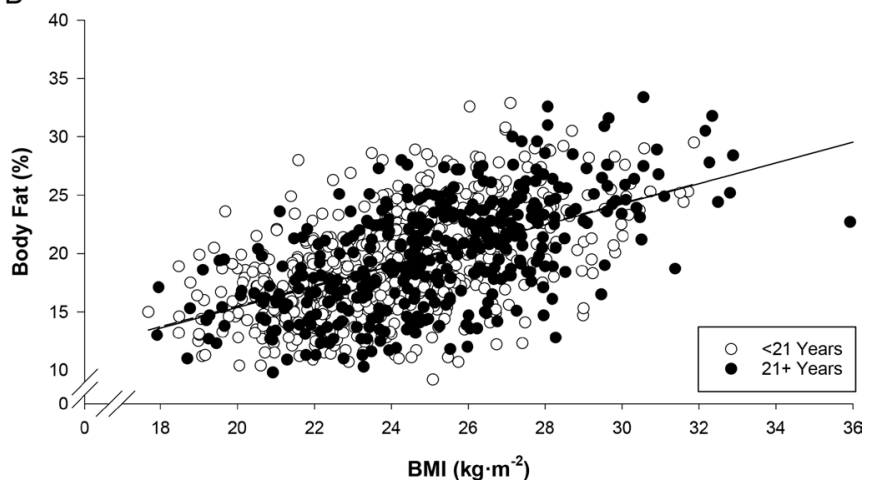

Figure 2 Relationship between $\mathrm{BMI}$ and per cent body fat in men at the start of BCT (A) and at the end of BCT (B). Data are separated by age, $<21$ years (open circles, dashed regression line) and $21+$ years (filled circles, solid regression line). BCT, basic combat training; BMI, body mass index.

$\mathrm{m}^{2}$, specificity is improved, but sensitivity is much lower, particularly in women.

Body composition at the lowest BMI $\left(<20 \mathrm{~kg} / \mathrm{m}^{2}\right)$

At the start of training, 46 women $(9.1 \%$ of all women) and 69 men $\left(7.2 \%\right.$ of all men) were below BMI $20 \mathrm{~kg} / \mathrm{m}^{2}$. The women and men were relatively lean (women: $26.6 \pm 3.8 \% \mathrm{BF}$; men: $15.8 \pm 3.8 \% \mathrm{BF}$ ), but also remarkably low in mean FFM and FFMI (women: $35.5 \pm 3.8 \mathrm{~kg}$ and $13.6 \pm 0.9 \mathrm{~kg} / \mathrm{m}^{2}$; men: $49.0 \pm 5.1 \mathrm{~kg}$ and $\left.15.6 \pm 0.9 \mathrm{~kg} / \mathrm{m}^{2}\right)$. By the end of training, the mean body mass in these two groups had increased from $49.7 \pm 4.0 \mathrm{~kg}$ to $52.6 \pm 4.3 \mathrm{~kg}$ (women) and from $59.6 \pm 5.2 \mathrm{~kg}$ to

Table 2 Relationships between BMI and \%BF

\begin{tabular}{lllll}
\hline Age/sex category & Timepoint & Predictive equation & $r^{2}$ & SEE (\%BF) \\
\hline Female & & & & \\
$<21$ years & Pre-BCT & $\mathrm{y}=1.19 x+4.05$ & 0.36 & 4.26 \\
& Post-BCT & $\mathrm{y}=0.97 \mathrm{x}+5.20$ & 0.26 & 3.72 \\
\hline $21+$ years & Pre-BCT & $\mathrm{y}=0.95 \mathrm{x}+9.26$ & 0.27 & 4.36 \\
& Post-BCT & $\mathrm{y}=0.79 x+8.79$ & 0.21 & 3.84 \\
Male & & & & \\
$<21$ years & Pre-BCT & $\mathrm{y}=1.22-7.83$ & 0.49 & 4.37 \\
& Post-BCT & $\mathrm{y}=0.88 \mathrm{x}-2.12$ & 0.28 & 3.74 \\
$21+$ years & Pre-BCT & $\mathrm{y}=1.14 \mathrm{x}-5.72$ & 0.48 & 4.58 \\
& Post-BCT & $\mathrm{y}=0.89 x-2.42$ & 0.31 & 4.05 \\
\hline
\end{tabular}

$\mathrm{BCT}$, basic combat training; \%BF, per cent body fat; $\mathrm{BMI}$, body mass index.
Table 3 Per cent body fat predicted by BMI $\left(25 \mathrm{~kg} / \mathrm{m}^{2}\right.$ and $27.5 \mathrm{~kg} /$ $\mathrm{m}^{2}$ ) for men and women, separated by age

\begin{tabular}{|c|c|c|c|c|}
\hline \multirow[b]{2}{*}{ Age/sex category } & \multicolumn{2}{|c|}{ BMI $25 \mathrm{~kg} / \mathrm{m}^{2}$} & \multicolumn{2}{|c|}{ BMI $27.5 \mathrm{~kg} / \mathrm{m}^{2}$} \\
\hline & Pre-BCT & Post-BCT & Pre-BCT & Post-BCT \\
\hline \multicolumn{5}{|l|}{ Female } \\
\hline$<21$ years & 33.8 & 29.4 & 36.8 & 31.9 \\
\hline \multirow[t]{2}{*}{$21+$ years } & 33.0 & 28.5 & 35.4 & 30.5 \\
\hline & & $29.4^{*}$ & & $32.4^{*}$ \\
\hline \multicolumn{5}{|l|}{ Male } \\
\hline$<21$ years & 22.6 & 19.9 & 25.7 & 22.1 \\
\hline \multirow[t]{2}{*}{$21+$ years } & 22.8 & 19.9 & 25.6 & 22.1 \\
\hline & & $18.6^{*}$ & & $21.6^{*}$ \\
\hline
\end{tabular}

${ }^{*}$ Deurenberg et al equation prediction for men and women aged $21 .{ }^{14}$ $\mathrm{BCT}$, basic combat training; $\mathrm{BMI}$, body mass index.

$63.0 \pm 6.2$ (men) and the mean FFMI increased to $15.0 \pm 1.0 \mathrm{~kg} /$ $\mathrm{m}^{2}$ (women) and $16.6 \pm 1.1 \mathrm{~kg} / \mathrm{m}^{2}$ (men).

\section{DISCUSSION}

The results demonstrate that at the end of BCT there is a leaner soldier population compared with civilian populations described in several other DXA-based national studies. Gallagher et al ${ }^{11}$ found that a BMI of $25.0 \mathrm{~kg} / \mathrm{m}^{2}$ predicted a $\% \mathrm{BF}$ of $35 \%$ and $23 \%$ for women and men in a large convenience sample. Heo et $a l^{12}$ analysed the combined 1999-2004 National Health and Nutrition Examination Survey data sets and found that a BMI of $25.0 \mathrm{~kg} / \mathrm{m}^{2}$ predicted slightly higher values for $\% \mathrm{BF}$ at $\sim 37 \%$ and $\sim 25 \%$ for women and men, with small differences between nonHispanic white, non-Hispanic black and Hispanic participants. These values roughly equate to the $36 \%$ and $26 \%$ BF used in Army standards for an upper limit of body fat permitted in the oldest $(40+$ years) male and female soldiers; these limits of $\% \mathrm{BF}$ in the Army regulation are anchored to chronic health thresholds derived backwards from a BMI of $25.0 \mathrm{~kg} / \mathrm{m}^{2}$ from 1980 s soldier data, ${ }^{1}$ and these most liberal relative body fat standards (but not the BMI of 25.0) may still be appropriate for health thresholds. Post-training BMI-\%BF relationships for men and women were very close to the predictions from the 1991 Deurenberg equation based on a fit and healthy Dutch cohort, ${ }^{14}$ with values as shown in Table 3.

The upper limits of \%BF in the US Army regulation are 30\% and $20 \%$ for those up to age 21 , and $32 \%$ and $22 \%$ for women and men ages $21-27 .{ }^{6}$ Based on the sensitivity analyses in this

Table 4 Sensitivity (correct detection of individuals above the $\% \mathrm{BF}$ value) and specificity (correct rejection of individuals below the $\% \mathrm{BF}$ value) of BMI classification of $\% B F$ for women and men in the total sample at the end of BCT

\begin{tabular}{llllll} 
& \multicolumn{2}{c}{ BMI $25.0 \mathrm{~kg} / \mathrm{m}^{2}$} & & BMI $27.5 \mathrm{~kg} / \mathrm{m}^{2}$ & \\
\cline { 5 - 5 } Body fat & Sensitivity (\%) & Specificity (\%) & & Sensitivity (\%) & Specificity (\%) \\
\hline Women & & & & \\
$30 \%$ & 55.1 & 79.0 & 15.1 & 98.1 \\
$32 \%$ & 62.4 & 74.5 & 13.8 & 95.2 \\
$34 \%$ & 61.7 & 69.4 & 8.5 & 93.4 \\
Men & & & & \\
$20 \%$ & 64.4 & 76.2 & 27.1 & 95.1 \\
$22 \%$ & 71.9 & 72.1 & 34.2 & 94.0 \\
$24 \%$ & 79.1 & 66.7 & 41.7 & 91.3 \\
\hline
\end{tabular}

$\mathrm{BCT}$, basic combat training; \%BF, per cent body fat; BMI, body mass index. 
study, setting the screening weight tables at a BMI of $27.5 \mathrm{~kg} / \mathrm{m}^{2}$ for men and women at any age could be used to identify those largest individuals who may exceed the body fat standards. ${ }^{23}$ BMI-based screening weights below 27.5 have a lower specificity and setting the levels lower may stigmatise many soldiers who are within body fat standards. The $27.5 \mathrm{~kg} / \mathrm{m}^{2}$ BMI cut point was the original recommendation of the $1985 \mathrm{NIH}$ Consensus Panel recommendations that defined obesity at a BMI of $>27.3$ (women) and $>27.8$ (men), drawn from the 85th percentile of the BMI for Americans aged 20-30years old at the time. ${ }^{24}$ It should again be underlined, consistent with many previous studies, that body fat is not well predicted by BMI; the very large variability in this relationship is evident in the scatterplots in Figures 1 and 2 and in the results described in Table 4. A better solution to modern military body composition standards might be to abandon this imprecise weight-for-height (BMI) screening with routine assessment of lean mass and relative fat against lower and upper sex-adjusted standards for every soldier.

Army standards for lower limits of body mass (BMI $>19 \mathrm{~kg} / \mathrm{m}^{2}$ ) attempt to ensure a minimum lean mass and reduce the number of musculoskeletal injuries in BCT, as the latter increase most dramatically at the lowest quintiles of BMI (women $<20.7 \mathrm{~kg} / \mathrm{m}^{2}$; men $\left.<21.7 \mathrm{~kg} / \mathrm{m}^{2}\right) .{ }^{25}{ }^{26} \mathrm{Just}$ as BMI is an inadequate surrogate of excessive fat, it is also an inadequate indicator of extremely low relative body fat. In this sample, recruits starting BCT below a BMI of $20 \mathrm{~kg} / \mathrm{m}^{2}$ averaged relative fat similar to fit young women and men (ie, 25\% BF and 15\% BF, respectively), instead of very low relative fat complemented by relatively higher FFM. Those individuals in the lower end of BMI represent a special subset of the emerging digital generation 'skinny fat' (metabolically obese normal weight), with recruits who may have a normal relative fat $(\% \mathrm{BF})$ and therefore an even lower than expected FFM. ${ }^{27}$ This particular group will not be flagged by current BMI screening for further body composition assessment. Therefore, different strategies that assess low levels of lean mass or reliance on fitness testing that requires greater demonstration of strength capability than the current Army fitness test are needed. Currently, the Army is moving to the new Army combat fitness test, which has strength and power-specific components. ${ }^{28}$ Training for this new fitness test is expected to further increase lean mass in women and men, resulting in bigger, stronger and leaner soldiers. ${ }^{29}$

Body composition continues to change into the third decade, with a non-continuous inflection in FFMI in the early 20s, where some stability in musculoskeletal development occurs. This transition to stable body composition merits further research, along with further focus on physical development trajectories of current digital-era girls and boys of premilitary age ( 14-18 years). Further examination of the influence of a fitness culture on expected age-related changes in body composition of ageing soldiers ( $>40$ years) is also merited.

\section{Study limitations}

An important caveat in the interpretation of BMI-\%BF relationships observed for women in this study is that this is an extrapolation from a relatively lean subset of the civilian population, reflecting the effects of a stricter weight screen in current Army female accession standards. Young women exceeding BMI $\sim 25 \mathrm{~kg} / \mathrm{m}^{2}$ are generally expected to meet entry body fat standards of $<32 \%$ (age <27). ${ }^{25}$ Therefore, the female soldiers in this study represent individuals who have been preselected on the basis of within-fat standards if they exceed BMI screening limits. This skews the relationship between BMI and body fat, but it represents the current accession and retention standards applied to female soldiers. Moving to a female weight-for-height screening based on BMI $27.5 \mathrm{~kg} / \mathrm{m}^{2}$ would increase weight allowances by $\sim 8-15$ lbs-. ${ }^{26}$

A second caveat is the effect of age. It is anticipated that a sample of older male and female soldiers may demonstrate increasing \%BF for BMI $27.5 \mathrm{~kg} / \mathrm{m}^{2}$, but this age group was not captured in the current analysis of predominantly young recruits. It should be noted that the age-related increase in $\% \mathrm{BF}$ has been accommodated by the Army's current age-related body fat limits, where $>40$ age limits are $36 \%$ and $26 \%$ BF for women and men. ${ }^{1}$

\section{CONCLUSIONS}

Attempts to predict $\% \mathrm{BF}$ from BMI are problematic due to human variability in body composition that is not simply accounted for by age and sex. In this study, US Army BCT also altered the relationship between BMI and adiposity, with lower $\% \mathrm{BF}$ at a given $\mathrm{BMI}$ at the end of BCT compared with the beginning, further highlighting the unreliability of BMI to try to estimate body composition. Furthermore, age was a discontinuous variable in this sample, with an inflection point in body mass, BMI and FFMI in the third decade. The very low end of BMI did not reflect an extraordinarily low \%BF but, rather, a normal relative fat with even lower than expected FFM. In addition to being an unreliable predictor of an individual's body composition, the specific BMI threshold of $25.0 \mathrm{~kg} / \mathrm{m}^{2}$, typically labelled 'overweight' and attributed to increased medical risk, is an outof-date metric for health and performance outcomes. To the extent that $\% \mathrm{BF}$ reflects physical readiness, these data provide evidence of a fit and capable military force at BMI greater than $25.0 \mathrm{~kg} / \mathrm{m}^{2}$.

Acknowledgements The authors thank the US Army Training and Doctrine Command Center for Initial Military Training for their support, as well as all the researchers and soldiers who participated in the data collection.

Contributors SAF, JH, SPP and KEF planned the body composition component of this study. SAF and JH submitted and led the study. SAF, JH, BAS, LAW, KIG and KMT collected and managed the data. SAF and KEF analysed and interpreted the data and wrote the first draft of the manuscript. All authors were involved in the final version of the manuscript.

Funding This study was funded by the Military Operational Medicine Research Program, US Army Medical Research and Materiel Command.

Disclaimer The opinions or assertions contained herein are the private views of the authors and are not to be construed as official or as reflecting the views of the Army or the Department of Defense.

Competing interests None declared.

\section{Patient consent for publication Not required.}

Ethics approval The study was approved by the Institutional Review Board of the US Army Medical Research and Development Command, Fort Detrick, Maryland.

Provenance and peer review Not commissioned; externally peer reviewed. Data availability statement No data are available.

Open access This is an open access article distributed in accordance with the Creative Commons Attribution Non Commercial (CC BY-NC 4.0) license, which permits others to distribute, remix, adapt, build upon this work non-commercially, and license their derivative works on different terms, provided the original work is properly cited, appropriate credit is given, any changes made indicated, and the use is non-commercial. See: http://creativecommons.org/licenses/by-nc/4.0/.

\section{ORCID iDs}

Stephen A Foulis http://orcid.org/0000-0002-3134-8427

KE Friedl http://orcid.org/0000-0002-8437-5058

\section{REFERENCES}

1 Friedl KE. Can you be large and not obese? the distinction between body weight, body fat, and abdominal fat in occupational standards. Diabetes Technol Ther 2004;6:732-49. 
2 Friedl KE, Leu JR. Body fat standards and individual physical readiness in a randomized army sample: screening weights, methods of fat assessment, and linkage to physical fitness. Mil Med 2002;167:994-1000.

3 Sanderson PW, Clemes SA, Biddle SJH. Prevalence and socio-demographic correlates of obesity in the British Army. Ann Hum Biol 2014;41:193-200.

4 Flegal KM, Graubard BI, Williamson DF, et al. Excess deaths associated with underweight, overweight, and obesity. JAMA 2005;293:1861-7.

5 Welham WC, Behnke AR. The specific gravity of healthy men: body weight $\div$ volume and other physical characteristics of exceptional athletes and of naval personnel. J Am Med Assoc 1942;118:498-501.

6 U.S. Department of the Army. The Army Body Composition Program. Army Regulation 600-9. Washington, DC: U.S. Department of the Army, 2019.

7 Wilmore JH, Behnke AR. An anthropometric estimation of body density and lean body weight in young men. J App/ Physiol 1969;27:25-31.

8 Wilmore JH, Behnke AR. An anthropometric estimation of body density and lean body weight in young women. Am J Clin Nutr 1970;23:267-74.

9 U.S. Department of Defense. Study of the military services physical fitness. Washington, DC: Office of the Assistant Secretary of Defense for Manpower, Reserve Affairs and Logistics, 1981.

10 Gallagher D, Visser M, Sepúlveda D, et al. How useful is body mass index for comparison of body fatness across age, sex, and ethnic groups? Am J Epidemiol 1996;143:228-39.

11 Gallagher D, Heymsfield SB, Heo M, et al. Healthy percentage body fat ranges: an approach for developing guidelines based on body mass index. Am J Clin Nutr 2000;72:694-701

12 Heo M, Faith MS, Pietrobelli A, et al. Percentage of body fat cutoffs by sex, age, and race-ethnicity in the US adult population from NHANES 1999-2004. Am J Clin Nutr 2012;95:594-602

13 Jackson AS, Stanforth PR, Gagnon J, et al. The effect of sex, age and race on estimating percentage body fat from body mass index: the heritage family study. Int $J$ Obes Relat Metab Disord 2002;26:789-96.

14 Deurenberg P, Weststrate JA, Seidell JC. Body mass index as a measure of body fatness: age- and sex-specific prediction formulas. Br J Nutr 1991;65:105-14.

15 Williams JE, Wells JCK, Wilson CM, et al. Evaluation of Lunar Prodigy dual-energy Xray absorptiometry for assessing body composition in healthy persons and patients by comparison with the criterion 4-component model. Am J Clin Nutr 2006;83:1047-54.
16 Foulis SA, Hughes JM, Walker LA, et al. Body mass does not reflect the body composition changes in response to similar physical training in young women and men. Int J Obes 2021;45:659-65.

17 Hughes JM, Foulis SA, Taylor KM, et al. A prospective field study of U.S. Army trainees to identify the physiological bases and key factors influencing musculoskeletal injuries: a study protocol. BMC Musculoskelet Disord 2019;20:282.

18 Knapik JJ, Darakjy S, Hauret KG, et al. Ambulatory physical activity during United States Army basic combat training. Int J Sports Med 2007;28:106-15.

19 Simpson K, Redmond JE, Cohen BS, et al. Quantification of physical activity performed during us army basic combat training. US Army Med Dep J 2013:55-65.

20 Ritland BM, Hughes JM, Taylor KM, et al. Sleep health of incoming army trainees and how it changes during basic combat training. Sleep Health 2021;7:37-42.

21 Crombie AP, Funderburk LK, Smith TJ, et al. Effects of modified foodservice practices in military dining facilities on AD libitum nutritional intake of US army soldiers. J Acad Nutr Diet 2013;113:920-7.

22 Toombs RJ, Ducher G, Shepherd JA, et al. The impact of recent technological advances on the trueness and precision of DXA to assess body composition. Obesity 2012;20:30-9.

23 Friedl KE. Body composition and military performance--many things to many people. $J$ Strength Cond Res 2012;26 Suppl 2:S87-100.

24 Kuczmarski RJ, Carroll MD, Flegal KM, et al. Varying body mass index cutoff points to describe overweight prevalence among U.S. adults: NHANES III (1988 to 1994). Obes Res 1997;5:542-8.

25 U.S. Department of the Army. Standards of Medical Fitness. Army Regulation 40-501. Washington, DC: U.S. Department of the Army, 2019.

26 Jones BH, Hauret KG, Dye SK, et al. Impact of physical fitness and body composition on injury risk among active young adults: a study of army trainees. J Sci Med Sport 2017:20:S17-22.

27 Foulis SA, Hughes JM, Friedl KE. New Concerns About Military Recruits with Metabolic Obesity but Normal Weight ("Skinny Fat"). Obesity 2020;28:223.

28 U.S. Department of the Army. Holistic Health and Fitness. Army Field Manual 7-22. Washington, DC: U.S. Department of the Army, 2020.

29 Kraemer WJ, Nindl BC, Ratamess NA, et al. Changes in muscle hypertrophy in women with periodized resistance training. Med Sci Sports Exerc 2004;36:697-708 